\title{
UK TRANSMISSION CONGESTION PROBLEM: \\ Causes and solutions
}

\author{
Dmitri Perekhodtsev \\ dperekhodtsev@lecg.com/LECG Consulting \\ Guido Cervigni \\ gcervigni@lecg.com/ LECG Consulting
}

6 January 2010 


\begin{abstract}
This paper focuses on transmission congestion issues that are currently experienced in the electricity market of the Great Britain. It analyses the nature of incentives and behavior of generators arising in presence of persistent congestion patterns due to constraint management approach employed in the GB market.

Although congestion in the GB market is often related to generators exercising market power, we demonstrate that this is not necessarily so. The observed behavior of generators is typical for generators having no market power when congestion patterns become persistent. Adverse incentives for such behavior are created by the redispatch type of congestion management approach used in the GB electricity market.

These adverse constraint incentives can be removed by a comprehensive modification of the market organization. In particular, market designs integrating energy market with congestion management using locational clearing prices seem at this point the most efficient approach in dealing with congestion. Several electricity markets have opted for this market design after having faced congestion issues similar to those currently experienced in the GB.

Modifications currently envisaged in the GB electricity market to resolve the problem, such as the introduction of Market Power License Condition, Transmission Access Review and the locational BSUoS, may not turn out to be adequate, providing at best a partial and temporal solution but not necessarily an integrated and comprehensive approach.
\end{abstract}

Kew words: Market power congestion constraints balancing mechanism 


\section{INTRODUCTION}

This paper discusses transmission congestion problems currently experienced in the GB electricity market as well as measures and modifications in the market organization currently considered by the British energy regulator Ofgem intended to resolve these problems.

The GB electricity market has experienced transmission congestion ever since the electricity market of the England and Wales was expanded to include Scotland in 2005. The connection capacity between Scotland and England was not sufficient for smooth operations of an integrated market, and recently this congestion problem became particularly severe resulting in unexpectedly high costs of resolving these constraints. Congestion mostly occurs on the England-Scottish border but is also present in other areas.

In this paper we show that the problem of high congestion costs in GB could be to a large extent due to the re-dispatch method by which the transmission congestion is currently dealt with in the GB electricity market. All markets transactions up to 1 hour before delivery are carried out as if there was unlimited transmission capacity to support the corresponding flows. That is, no rationing of the existing transmission capacity takes place at this stage. Then in case if the resulting market schedules are infeasible due to transmission constraints, the Transmission System Operator relieves the congestion in the balancing market, accepting offers of generators to increase output and bids to buy power back in particular locations.

Such re-dispatch method of dealing with congestion may provide reasonable results when congestion is rare and unpredictable. However, this method is known to create severe problems when congestion becomes persistent. In this case the redispatch method creates adverse incentives for both short-run bidding behaviour and for long-term investment decisions. In the short-run it sets different bidding competitive benchmarks on the opposite sides of the constraints. When rational and competitive market participants offer their capacity into the market according to this modified competitive benchmark, their offers and bids tend to further increase 
congestion and the cost of its relief. In the long run, generators may find profitable to build highly inefficient plants in the export constrained locations with the intention to collect the constraint-off payments without generating.

As a result of the incentives created by the re-dispatch congestion management, congestion costs increase very rapidly as soon as congestion patterns become persistent and predictable. Importantly, these incentives are generally unrelated to market power and can be experienced by all generators, even the smallest ones having no market power. However, the GB congestion problems have often been related by market observers with allegedly non-competitive behaviour of market players exacerbating the constraint cost. The British energy regulator Ofgem currently considers introducing a new Market Power License Condition. This condition will consider certain behaviours of generators as undue exploitation of market power. However, it is likely that the criteria set up in the new MPLC will largely be limiting the competitive incentives created by the current congestion management system during the constraint situations.

There exists a solid and an integral approach to solve this congestion management problem. Many electricity markets internationally that have suffered from the similar problem in their early years have eventually adopted this method. It appears that currently the GB market needs to follow this example. This approach consists of two major elements:

- Recognizing that due to congestion, market cannot be presumed unconstrained at any stage. The existing transmission capacity is rationed simultaneously with market transactions by introducing a market with locational pricing. This could take a simple form of market splitting as it is done currently in Italy, Nordic countries and in the integrated tri-lateral market of France, Belgium and the Netherlands. A more rigorous approach could take form of nodal pricing like in several markets in the United States and New Zealand.

- Introduction of the system of financial transmission rights and developing rules for their allocation. This step is necessary to hedge the market participants against 
the congestion risk and to help market players make long-term deals. The allocation rules of the financial transmission rights can be designed in a way to honor the historic transmission rights existing prior to the transition to the locational pricing system.

This approach could allow solving many of the incentive problems currently faced in the GB and to allocate the available transmission capacity in the most efficient way.

The GB currently considers several modifications in the market organization intended to deal with the mounting congestion issues. Some elements of these modifications resemble the locational pricing mechanisms.

- First is the series of market rule changes called Transmission Access Review (TAR) led jointly by Ofgem and the Department of Energy and Climate Change. Although the original objective of TAR is promoting the development of renewable wind power in Scotland, it tackles some of the related congestion issues as well. For example, some proposals of the TAR suggest market-based mechanisms of rationing the existing transmission capacity.

- Second is the introduction of locational BSUoS payments. Currently, payments compensating the TSO for congestion management costs are charged uniformly to customers and generators across the entire GB. The proposed modification considers making market participants paying for the balancing actions in their location.

Although these modifications may introduce some elements of the locational markets, they do not seem to represent an integral and comprehensive solution, being rather a set of patches intended to improve the situation while preserving the existing system to the extent possible. It is unclear at this stage how these market amendments as well as the new MPLC would interact with each other and whether together they will lead to the desired result.

In this paper we discuss the proposed changes of the UK congestion management system, by benchmarking them against the (standard) locational price 
based approach, providing examples from international electricity markets. We discuss the proposed changes both from a general market design perspective and in relation to their specific objectives pursued in the UK.

The remainder of the paper is structured as follows:

Section II describes the approach to congestion management used in the GB electricity market and the recently observed congestion issues; Section III illustrates the incentives created by the GB congestion management mechanism and discusses their competitive nature; Section IV describes the efficient congestion management approach based on locational clearing prices and compares it to the ongoing GB market design modifications; Section V provides conclusion to this paper.

\section{CONGESTION ISSUES IN THE BETTA MARKET}

\section{A. Addressing congestion in the GB electricity market}

The current arrangements for trading electricity in Great Britain are known as the British Electricity Trading and Transmission Arrangements (BETTA). ${ }^{1}$ BETTA sets out the rules under which generators may compete to supply electricity buyers using the transmission system that runs throughout England, Wales and Scotland. Two elements of the BETTA trading arrangement are most important in relation to the transmission congestion management: the forward bilateral market and the Balancing Mechanism (BM).

Market participants perform bilateral electricity trades in the forward markets. Such trades are continued until the "gate closure", which is set at one hour before the relevant half hour period. In such bilateral trades parties are free to trade across the entire GB market and no transmission limitations to such trades are explicitly considered at this stage. At 11am the National Grid acting as a Transmission System Operator collects from the parties their contractual positions for each of half-hour

\footnotetext{
${ }^{1}$ In April 2005 BETTA has replaced 'NETA' which applied only to England and Wales. NETA in turn has replaced the Electricity Pool in 2001, which operated only as a spot market.
} 
period of the following day (the Initial Physical Notification or IPN). These positions can be modified before the "gate closure".

At "gate closure" the forward bilateral market stops; contract positions of the participants submitted to the National Grid constitute the Final Physical Notification or FPN. During the remaining hour National Grid acting as Transmission System Operator runs the Balancing Mechanism in which it accepts offers and bids of generators to increase or to decrease output, acting as a sole counterparty to these trades. One of the purposes of the Balancing is to deal with transmission congestion. In case if schedules resulting from the FPN are infeasible because of transmission capacity limitations, the National Grid accepts the balancing offers to increase output from generators in the import-constrained area and balancing bids to reduce output from generators in the export-constrained area. Generators whose offers are accepted are paid the price of their offer for each accepted MWh. Generators whose bids are accepted pay to the National Grid the price of their bid for each reduced MWh, while keeping the original contract position fully honored.

National Grid may use other tools to balance the system and to resolve constraints in addition to the Balancing Mechanism. These tools include pre-gate balancing trades or PGBT, that is, bilateral contracts with individual power plants stroke before the "gate closure" and commercial inter-trips, that is, contracts with individual plants giving the ability to the National Grid to expand the transmission limits by disconnecting the plant in case if the line gets overloaded [1].

The general approach to congestion management used in the GB market is common in many European countries, such as France, Netherlands, Spain and Germany. This approach referred to as re-dispatch is characterized by two distinct steps:

- First, market transactions are cleared as if available transmission capacity were adequate to support any flow resulting from the trades. At this stage a geographically uniform clearing price prevails. 
- In the second stage the re-dispatch is performed to adjust the original market solution to make it feasible given the network constraints. At this stage market participants are compensated by the Transmission System Operator (TSO) for deviations from the level of injections and withdrawals that would result in the absence of transmission constraints.

Partly, the rationale for such market organization is the anticipation that congestion within each national market is rare and sporadic and that little re-dispatch would be required to make the unconstrained market solution feasible.

\section{B. Historic congestion costs}

Limited transmission capacity between Scotland and England was acknowledged in 2005 during the expansion of the electricity wholesale trading arrangements to include Scotland at the time when BETTA decisions were taken. The connection capacity between Scotland and England was often insufficient for smooth operations of an integrated market, and recently this congestion problem became particularly severe. Moreover, the level of congestion costs observed in reality has far exceeded all anticipations [2].

Table 1 below shows Ofgem's figures summarizing information on the level of constraint costs since the implementation of BETTA on 1 April 2005 providing separately the information on constraints related to the Scottish constraints.

Table 1. Historical trends in constraints costs

\begin{tabular}{|c|c|c|c|c|c|c|}
\hline \multirow[b]{2}{*}{ Period } & \multicolumn{2}{|c|}{$\begin{array}{l}\text { Constraints Costs } \\
\text { (£’ million) }\end{array}$} & \multicolumn{2}{|c|}{$\begin{array}{l}\text { Volume of Actions } \\
\text { (GWh) }\end{array}$} & \multicolumn{2}{|c|}{$\begin{array}{l}\text { Average Price of } \\
\text { Actions (£/MWh) }\end{array}$} \\
\hline & GB & Scotland & GB & Scotland & GB & Scotland \\
\hline $2005 / 06$ & 84 & 70 & & & & \\
\hline 2006/07 & 108 & 80 & & & & \\
\hline 2007/08 & 70 & 42 & & & & \\
\hline $2008 / 09 *$ & 238 & 210 & 4,976 & 4,430 & 47.8 & 47.5 \\
\hline 2009/10* & 262 & 212 & 9,605 & 3,538 & 27.4 & 60 \\
\hline
\end{tabular}

Notes: *Forecasted values 
Source: [1]

The levels of forecasted Scottish constraint costs for 2009/10 are over three times those experienced in the first year following the implementation of BETTA. Ofgem emphasizes that the increase in the constraint costs in 2008/09 and 2009/10 was unprecedented and unexpected. Previous year forecast made by the National Grid for the constraint costs in 2008/9 was only $£ 124$ million, whereas the current forecast has increased to $£ 238$ million[1].

\section{Adverse bidding incentives in the Balancing Mechanism}

Ofgem has been concerned that the increase of the congestion costs has been caused by particular bidding behaviour of generators in the Balancing Mechanism creating congestion and exacerbating the congestion costs.

The study performed by Ofgem suggests that Scottish generators submit bids

lower than comparable generators in England during the periods of congestion on the Anglo-Scottish boundary in the direction of England, that is, during the export constraint. They also submit higher offers than comparable plants in England when congestion is in the direction of Scotland, that is, during the import constraint.

This bidding behaviour of generators in Scotland is illustrated by the figures below. Figure 1 shows a comparison between the weekly average volume-weighted bid prices accepted in the Balancing Mechanism of gas plants in England/Wales and in Scotland from April 2005 to August 2008. Ofgem has also identified periods of an export constraint situation based on the "tagged” data from National Grid on constraint-related actions. These periods are shaded on the graph below. 
Figure 1. Accepted BM Bids in constrained and non-constrained periods, Scottish gas plant versus E\&W gas plant April 2005-August 2008

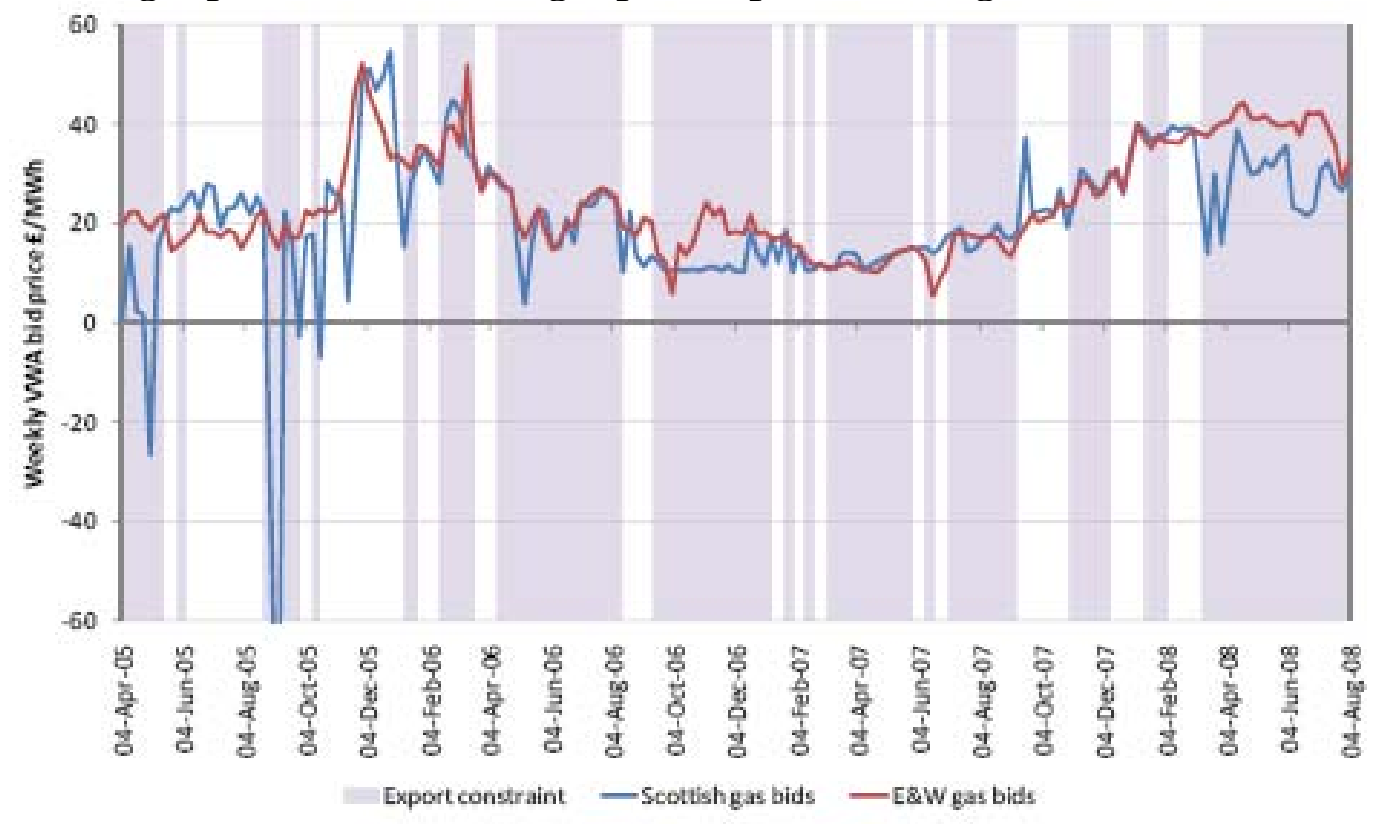

Source: [1]

The figure suggests that the export constraint situations have been rather frequent in Scotland since the start of BETTA. During many of them bid prices submitted in Scotland were below those of comparable English plants, in particular in summer 2008 and in fall 2006. The figure also shows several episodes of consistent negative bid prices during export constraint periods.

Figure 2 below shows similar comparison for between offer prices of coal plants accepted in the Balancing Mechanism in England/Wales and Scotland in 2007. Shaded areas represent the constraint situations in the direction of Scotland, that is, import constraints. 
Figure 2. Accepted BM offers in constrained and non-constrained periods Scottish coal plant versus E\&W coal plant Jan-Dec 2007

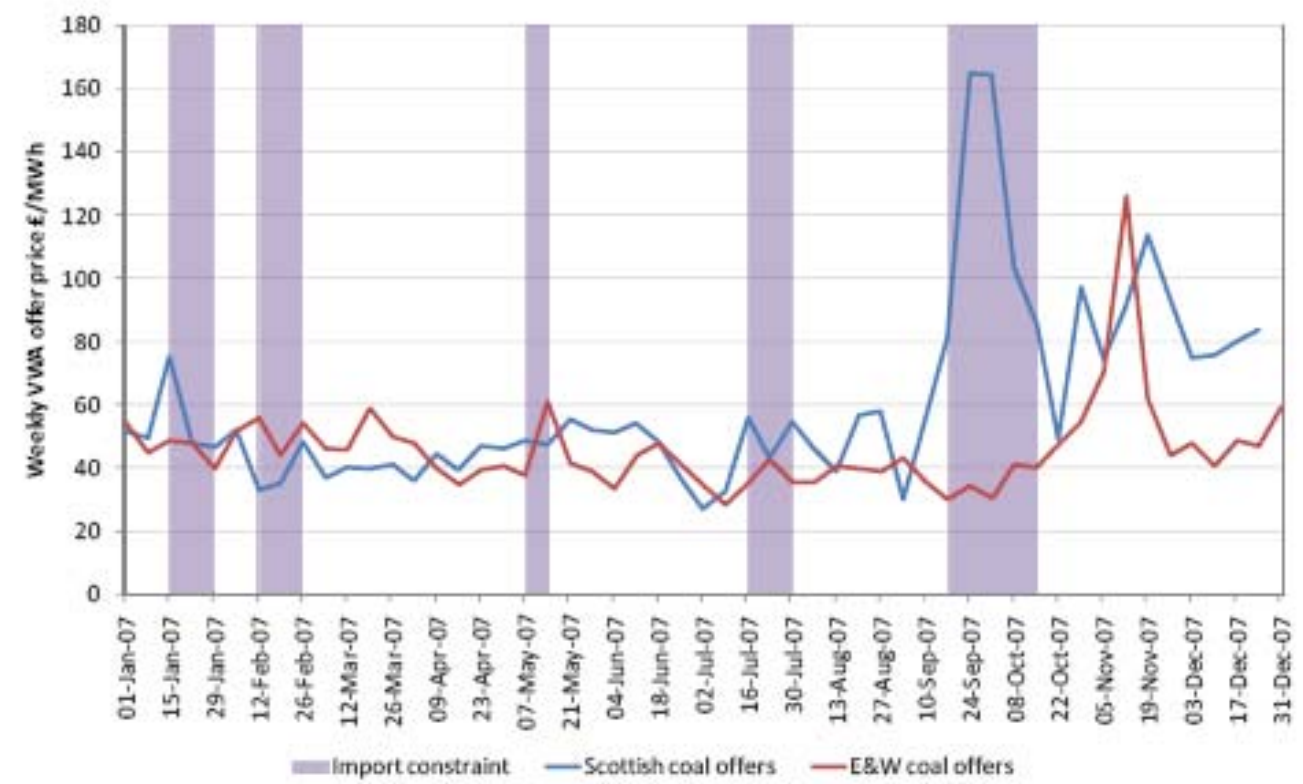

Source: [1]

The figure suggests that Scottish offers exceed the offers submitted for comparable plants in England during the Scottish import constraints. This difference is particularly apparent on the weeks of January 15 and July 16 . The spike of the accepted Scottish offer prices in September and October 2007 was the object of Ofgem investigation.

Table 2 below shows the average prices of accepted bids in England \& Wales and in Scotland for coal and gas plants depending on the constraint situation.

The table suggests that Scottish bids are significantly lower than bids of comparable generators in England \& Wales in presence of export constraint, while the bids are similar throughout the GB in the absence of the constraint. 
Table 2. Volume-weighted average accepted bid prices (£/MWh), April 2005 to June 2008

\begin{tabular}{ccccc}
\hline \multirow{2}{*}{ Plant technology } & Export constraint & Scotland & E\&W & Difference \\
\hline \multirow{2}{*}{ Coal } & Yes & 11.8 & 25.6 & -13.8 \\
& No & 22.6 & 24.6 & -2.1 \\
& Difference & -10.8 & 1 & \\
\hline \multirow{2}{*}{ Gas } & Yes & 15.7 & 25.2 & -9.5 \\
& No & 25 & 25.8 & -0.8 \\
& Difference & -9.3 & -0.6 & \\
\hline
\end{tabular}

Source: [1]

Based on these figures and tables Ofgem concludes that the Scottish generators Scottish Power and Scottish \& Southern Energy may have behaved in ways that "exacerbated, and in some cases created, constraint situations in relation to Scotland”.

\section{Congestion, bidding and market power}

Bidding behaviour identified above was often considered as evidence of the exploitation of market power. In April 2008 Ofgem has launched a formal investigation under the Competition Act 1998 (CA98) into the behaviour of the two major Scottish generators, Scottish Power (SP) and Scottish \& Southern Energy (SSE).

The two Scottish companies have allegedly abused a position of dominance vis-à-vis the relief of the import constraint into Scotland in September and October 2007. In particular, the two companies failed to schedule the generating plants in the wholesale forward market, but offered the same plants in the Balancing Market at allegedly excessive prices [3].

In the recent consultation Ofgem notes that similar concerns had been raised on several occasions since BETTA was introduced.

During the investigation of the constraint situation in September and October 2007 it was found that such behaviour included "the apparent withholding of " in 
merit" plant during import constraints despite positive spreads being available in the forward market”. Other periods were identified in which either or both generators appeared to be running plant "out of merit" during export constraints [1].

After a recent public consultation regarding the best way to address these market power issues, Ofgem has come to a decision to introduce a Market Power Licence Condition (MPLC) on generators [4]. Such license condition is expected to strengthen Ofgem's powers to carry out ex-post investigations of generators' behaviour and impose fines or other sanctions if participants were found to be exploiting unduly a position of market power.

According to the recently passed Energy Bill, which includes the MPLC provisions, the Ofgem will consider the following market behavior as evidence of undue market power exploitation [5]:

- Output manipulation. This includes failure of generators located in importconstrained areas to sell forward and self-schedule plants whose cost is below the forward market price. Similarly, this includes self-scheduling by generators in the export-constrained areas of plants whose costs put them out of merit compared to the forward market price. Such behaviour is considered as "manipulation and exacerbating of constrain costs”.

- Exploitative bidding. This includes submitting excessively high balancing offers by plants behind the import constraints to extract unduly high constraint-on payments from National Grid, and submitting excessively low balancing bids by plants behind export constraints to extract unduly high payments for being constrained-off. 


\section{INCENTIVES INDUCED BY THE BALANCING MECHANISM}

\section{A. Competitive bidding benchmark in the constraint situation}

Bidding behaviour that, according to Ofgem, exacerbates the constraint costs and that could be the result of market power exploitation is the direct consequence of the re-dispatch congestion management approach employed in the GB electricity market. Such bidding behavior is induced by the re-dispatch mechanism when congestion patterns become persistent and anticipated by market participants. When followed by market participants, these incentives may have major adverse impacts on the market.

Congestion anticipated by market players modifies competitive bidding benchmark on both sides of the constraint. The resulting bidding incentives are followed by any generator regardless of its size and market power.

In particular, two features of the GB congestion management mechanism are responsible for this incentive problem:

- Existence of two markets, forward bilateral market and the Balancing Mechanism, one of which disregards the limitations of the transmission system, while the other respects them. In presence of congestion, this creates arbitrage opportunity between the unconstrained forward market and the Balancing Mechanism. An expected constraint situation may make one market more profitable for a generator than the other one depending on which side of constraint this generator is located.

- Pay-as-bid clearing in the Balancing Mechanism. This creates the incentive to submit offers and bids in the Balancing Mechanism at a price equal to the expected cost of the most expensive unit running in a given area. This cost is higher than the nation-wide price in case of import constraint and lower in case of export constraint.

In an import-constrained area the cost of the last running unit (marginal cost) is generally higher than the cleared price in the unconstrained market. Therefore, 
even if all balancing offers represented generating cost, one could expect that in case of congestion, balancing offers higher than nation-wide price will be accepted in the import-constrained area. Generators in this area may anticipate earning higher profits in the Balancing Mechanism if their offers are accepted for re-dispatch than from selling power in the unconstrained forward market. Such generators would value their plants in the import-constrained area higher and, as a result, these plants may not get scheduled in the forward market even if they are economic to run given the nation-wide price in the unconstrained market ${ }^{2}$. However, balancing offers reflecting this high valuation in the import -constrained area may still clear in the Balancing Mechanism. Both the offering in the forward and balancing markets in this case will be aligned with the expected marginal cost in the import-constrained area.

Conversely, in an export-constrained area even if all balancing bids are set at generating cost, balancing bids accepted in the export-constrained area will be below nation-wide price. Generators expecting to be in the export-constrained area anticipate that in the Balancing Mechanism they will be able to buy their power back from National Grid at a price lower than the nation-wide price. They will ensure their power is scheduled in the forward market even if this might be uneconomic given the unconstrained clearing price. Then, they will get a balancing bid below nation-wide price accepted in the Balancing Mechanism, allowing them earning the difference between the nation-wide price and the accepted bid price. Both the offering in the forward and balancing markets in this case will be aligned with the expected marginal cost in the export-constrained area.

The impact of such change of the competitive benchmark on the market outcomes could be rather dramatic. First, generators offering into the unconstrained market according to the modified competitive benchmark tend to further increase congestion and the cost of balancing actions needed to resolve constraints. Second, the modified offering in the unconstrained market may have an impact on the clearing price in this market.

\footnotetext{
2 The operator may have a requirement to schedule generation in balance with its load by the gate closure. This requirement could still be met by contracting with generators on the other side of the import constraint.
} 
In the examples below we illustrate in more detail the formation of the new competitive benchmark for energy bidding in the import- and export-constrained areas and its impact on the market outcomes.

\section{Offering in the import-constrained area}

Figure 3 below illustrates the case of an import constraint. In this example the import-constrained area contains a sufficient number of generators to assume perfect competition in the area. These generators have identical capacity but various variable costs.

Figure 3. Competitive bidding in the import-constrained area
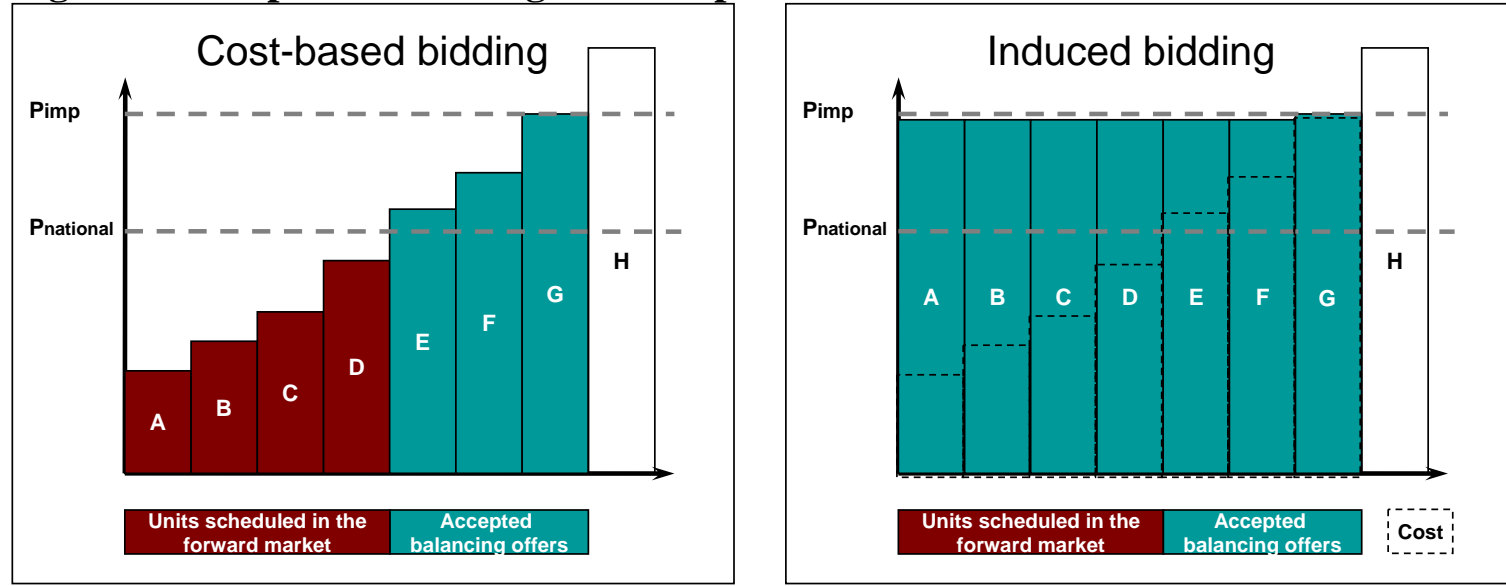

The left panel of the figure shows the cost merit order of units located in the import-constrained area. Generators A to D have marginal costs less than the unconstrained nation-wide price of the forward bilateral market; at this price they are "in the money" and in the absence of constraint they would be scheduled in the forward market. Generators $E$ to $G$ have a higher variable cost than the nation-wide price, however, these units are the most economic to constraint-on to relieve the import constraint. In this example we assume that seven units need to run in this area to relieve the import constraint. The constraint is relieved most economically if units A to $\mathrm{G}$ are turned on.

In case if this constraint situation was predicted by all generators in the area with reasonable certainty, the cost of the last generator running in the area as a result 
of the economic re-dispatch, that is, the cost of the generator G, would set a new competitive benchmark for offering of all generators whose cost is below this benchmark.

The price of offers of generators $\mathrm{E}$ and $\mathrm{F}$ in the Balancing Mechanism would be just below the cost of the generator G. Such offers would be accepted for redispatch and would receive the price of the highest accepted re-dispatch offer.

Generators A to D would realize that if they had offered their units in the Balancing Mechanism instead of the unconstrained forward market, they could have earned the price of the highest accepted re-dispatch, which is higher than the nationwide forward price.

To achieve this profit they would have to make sure their units are not cleared in the forward unconstrained market and thus, are eligible to submit offers in the Balancing Mechanism. They can do that for example by offering their units in the forward market at a price above the nation-wide forward price. The opportunity cost of offering in the forward market will be equal to the expected cost of the last accepted unit in the Balancing Mechanism in the import-constrained area.

The resulting competitive bidding induced by the predicted import constraint situation and the re-dispatch congestion management mechanism is presented in the right panel of the Figure 3. All units, with costs below the cost of the last accepted offer, submit balancing offers at or just below this level. This price level is also used for offering into the forward unconstrained market by units whose costs are also the forward price. As a result these units are not cleared in the forward market even though some of them may seem "in the money".

Thus, the cost of the last economic unit running in the import-constrained area sets the new competitive benchmark both for the forward market and for the Balancing Mechanism offering of all units in the area whose cost is below that level.

This bidding strategy may present risks in case if the anticipated level of congestion does not materialize. In this case generators may end up not being 
constrained on when they are "in the money" in the forward market. However, this risk becomes less material if congestion is persistent.

\section{Bidding in the export-constrained area}

Figure 4 below illustrates the export situation. As before, in this example the export-constrained area contains a sufficient number of generators to assume perfect competition in the area. These generators have identical capacity but various variable costs.

Figure 4. Competitive bidding in the export-constrained area
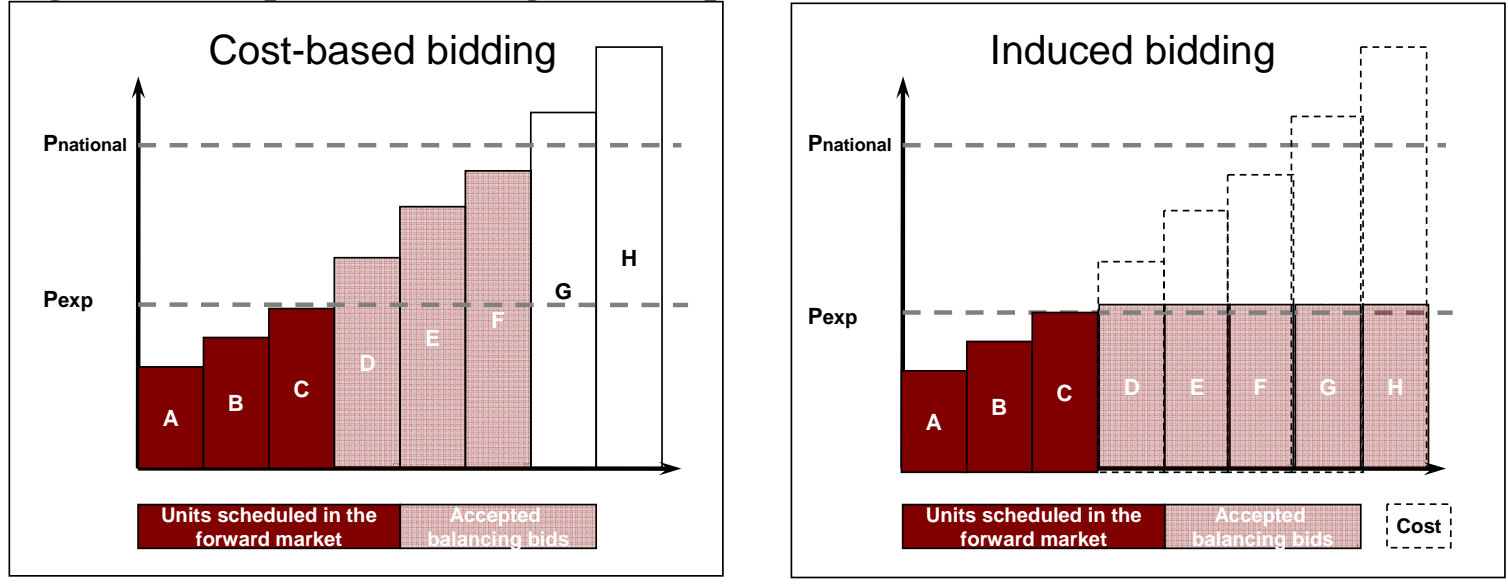

These costs are illustrated in the left panel of the figure. Generators A to F in this example have marginal costs lower than the nation-wide forward price and at this price they are economic to run. However, because of the export constraint from the area, certain output has to be constrained-off. In this example we assume that to relieve the export constraint, only three units should be running in this area.

Generators D, E and F having the highest cost are the most economic choice to be constrained-off.

In case if this export constraint situation was predicted by all generators in the area, the cost of the last generator running in the area as a result of the economic redispatch, the generator $\mathrm{C}$, would set a new competitive benchmark for bidding for all generators whose cost is above this benchmark. 
Generators D, E, and F that could be scheduled in the forward market given their costs below the forward price, would submit balancing buy-back bids at the level at or just above this competitive benchmark, which is lower than their costs. Such price level would guarantee that the balancing bid is accepted allowing the generators to buy power back at the lowest available price. Since for the constrainedoff generators the sales done in the forward market are still honored, the profit of these generators from bidding at the new competitive benchmark is equal to the difference between the nation-wide forward price and the last accepted bid in the export-constrained area.

In addition, when congestion is expected, generators $\mathrm{G}$ and $\mathrm{H}$ that are not "in the money” since their costs are above the nation-wide price, may still find it profitable to participate in the Balancing Mechanism and to receive profits equal to the difference between the forward price and the last accepted bid. To achieve these profits they need to make sure their capacity is sold in the nation-wide forward and thus is eligible to submit buy back balancing bids. To do so they sell in the unconstrained market below cost.

The right panel of Figure 4 illustrates the outcome of the competitive bidding incentives induced by the anticipated export constraint situation and the re-dispatch congestion management. All plants with costs above the highest cost of units running in the export-constrained area are scheduled in the forward market. Then their balancing bids submitted at the level of expected cost of the most expensive unit running in the export-constrained area are accepted in the Balancing Mechanism. These units receive profits equal to the difference between the nation-wide price and the last accepted bid in the area.

Thus, the cost of the last economic unit running in the export-constrained area can be considered the new competitive benchmark for forward market and Balancing Mechanism offering of all units in the area whose cost is above that level.

This bidding may present risks in case if the anticipated level of congestion does not materialize. In this case generators may end up running at loss when 
forward price is above their costs. However, this risk becomes less material if congestion patterns are persistent and generators can be certain about them.

\section{Impact on the market outcomes}

The following example illustrates the impact of the bidding incentives induced by the anticipation of the congestion on overall market outcomes, such as the market price, volume and the cost of congestion re-dispatch. We assume a two-node market; demand in node A is $50 \mathrm{MW}$ and in node B $400 \mathrm{MW}$. Available transmission capacity between node A and B is $100 \mathrm{MW}$. The generators located in zone A and zone B have capacities and generating costs as shown in Table 3 and illustrated in Figure 5.

Table 3. Generators' capacity and costs

\begin{tabular}{lcc|cc}
\hline Generator's name & A1 & A2 & B1 & B2 \\
\hline $\begin{array}{l}\text { Generator's capacity } \\
(\mathrm{MW})\end{array}$ & 200 & 200 & 200 & 200 \\
$\begin{array}{l}\text { Generator's Variable } \\
\text { Cost (£/MWh) }\end{array}$ & 10 & 30 & 20 & 50 \\
\hline
\end{tabular}

Figure 5. Least-cost feasible dispatch

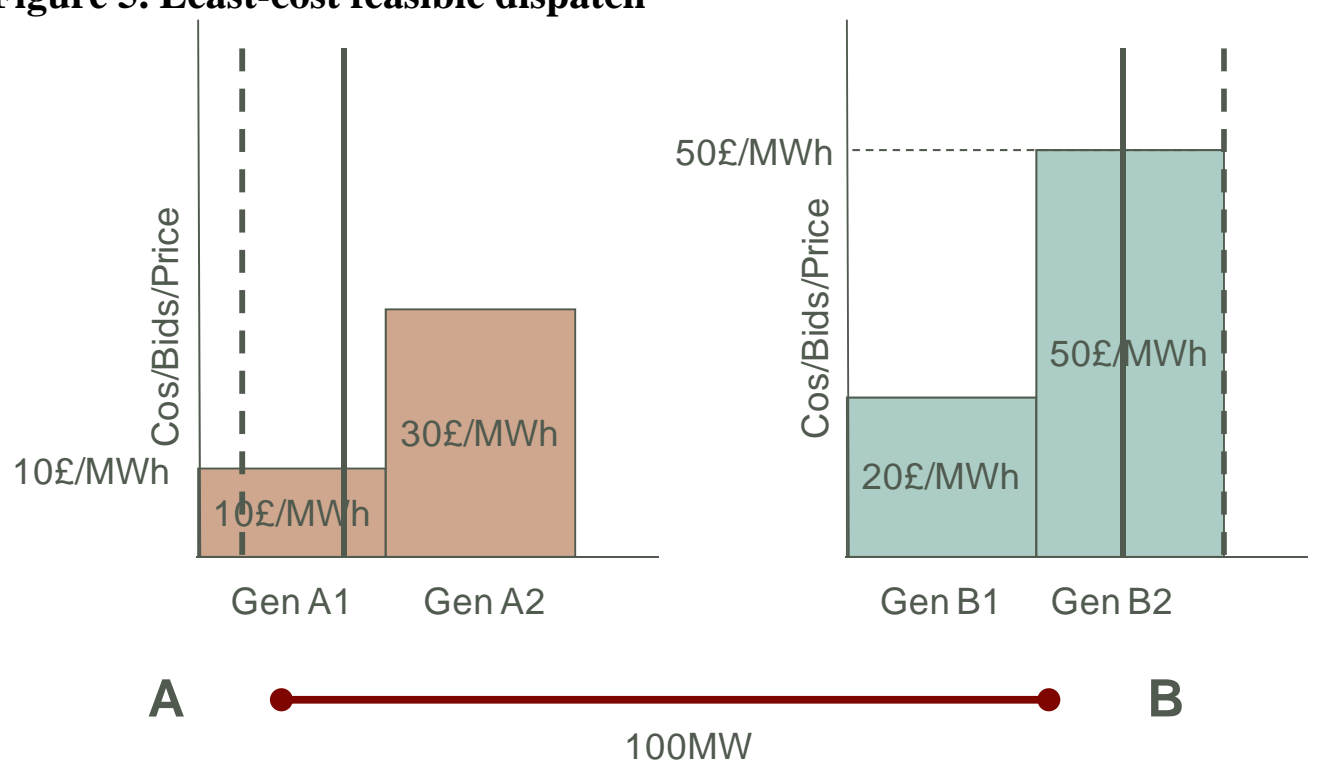


The small number of generators is chosen for simplicity of illustration. However, we assume, that these generators behave competitively, following the bidding incentives described above.

We start by computing the cost-minimizing dispatch that is feasible given the transmission capacity; we also compute the resulting marginal costs of energy in each location. In node A, $150 \mathrm{MWh}$ are accepted and the marginal cost is set by Gen A1 at $10 £ / M W h$. In node B, 300MWh are accepted and the marginal cost is set by Gen B2 at 50 £/MWh. This outcome is illustrated in Figure 5.

Now consider the equilibrium in the market in which congestion is managed by re-dispatch as it is done in the electricity market of GB. If all generators had actually scheduled their capacity in the forward bilateral market according to the costs, the market outcome would be as presented in Figure 6 .

\section{Figure 6. Unconstrained market assuming bidding at cost}

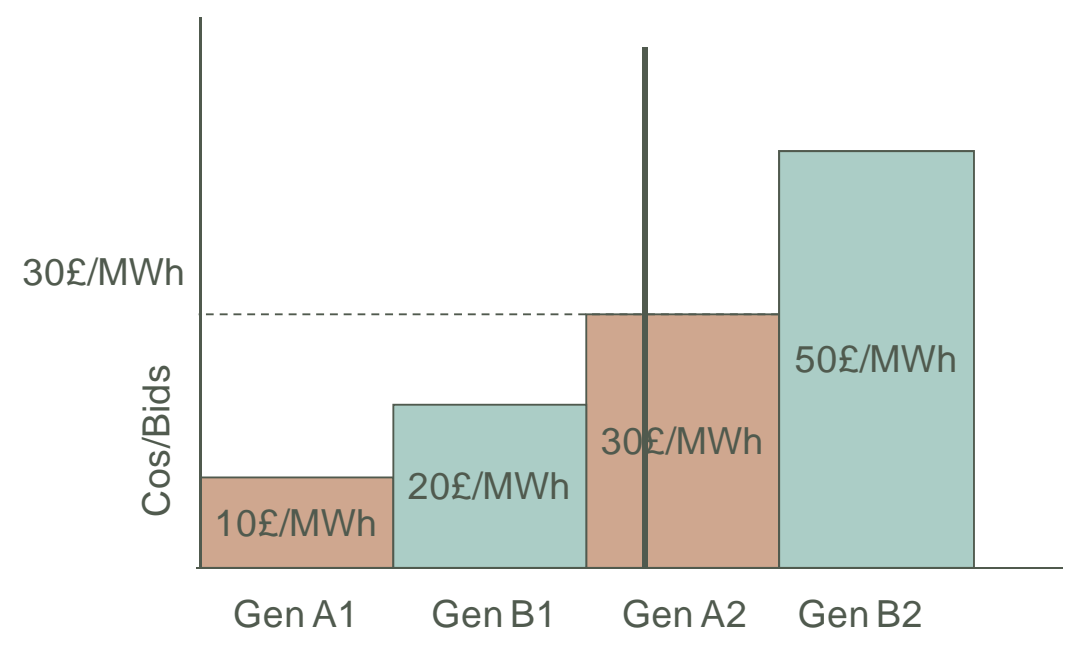

The demand is cleared by Generator A2 at the nation-wide price of 30 £/MWh. However, this dispatch is infeasible since it results in $200 \mathrm{MWh}$ flow from A to B and a re-dispatch of $100 \mathrm{MWh}$ from B to A is necessary. If offers and bids of generators in the re-dispatch market were also equal to the costs, the re-dispatch parameters would be as presented in Table 4 below. 
Table 4. Re-dispatch in case of cost-based offers and bids

\begin{tabular}{cccc} 
Generator & $\begin{array}{c}\text { Re- } \\
\text { Re- } \\
\text { dispatch, } \\
\text { MWh }\end{array}$ & $\begin{array}{c}\text { dispatch } \\
\text { cost } \\
\text { E/MWh }\end{array}$ & $\begin{array}{c}\text { Total re- } \\
\text { dispatch } \\
\text { cost, } £\end{array}$ \\
\hline A1 & -50 & 10 & -500 \\
A2 & -50 & 30 & -1500 \\
B1 & 0 & 20 & 0 \\
B2 & 100 & 50 & 5000 \\
\hline Total & & & $\mathbf{3 0 0 0}$ \\
\hline
\end{tabular}

The total cost of such re-dispatch leading from the unconstrained cost-based market outcome shown in Figure 6 to the least-cost feasible dispatch shown in Figure 5 is $3000 £$.

However, generators would bid differently if they have expected this level of congestion and this re-dispatch. This expectation would affect both the offering in the unconstrained forward market and offers and bids in the re-dispatch balancing market.

Generator A2, anticipating that it will be constrained-off in the balancing market and that marginal cost in area A will be $10 £ / \mathrm{MWh}$ will offer its capacity at a price close to $10 \mathrm{E} / \mathrm{MWh}$ in the bilateral market. At the same time, Generator B1, anticipating that in its location Generator B2 will be constrained-on at a marginal cost of $50 £ / M W h$ will offer its capacity close to this price in the nation-wide forward market. The outcome of the unconstrained forward market is shown in Figure 7 below. 
Figure 7. Unconstrained market when constraints are anticipated

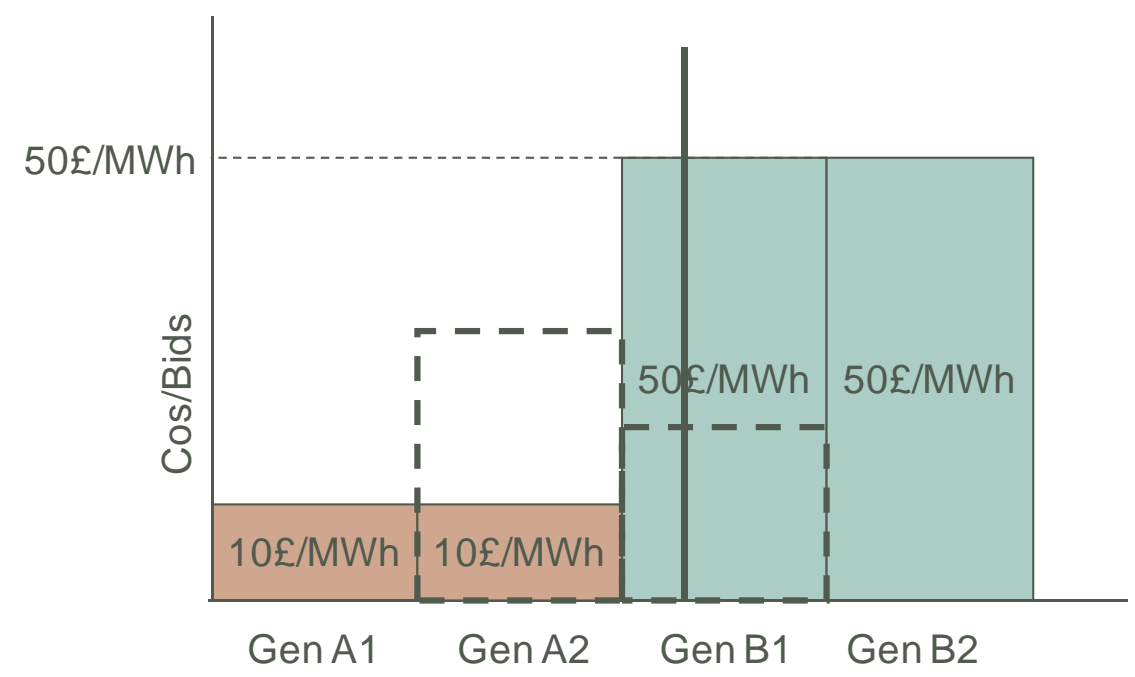

The market price in this market would be set at $50 £$ /MWh. This forward schedule now results in the flow of $350 \mathrm{MWh}$ from A to B. Thus, a re-dispatch of $250 \mathrm{MWh}$ from B to A is necessary. Given the level of offers and bids equal to the marginal cost in each location, the re-dispatch is summarized in Table 5.

\section{Table 5. Re-dispatch in case of bidding induced by re-dispatch method}

\begin{tabular}{cccc}
\hline Generator & $\begin{array}{c}\text { Re- } \\
\text { dispatch, } \\
\text { MWh }\end{array}$ & $\begin{array}{c}\text { Re- } \\
\text { dispatch } \\
\text { cost } \\
£ / \text { MWh }\end{array}$ & $\begin{array}{c}\text { Total re- } \\
\text { dispatch } \\
\text { cost, } £\end{array}$ \\
\hline A1 & -50 & 10 & -500 \\
A2 & -200 & 10 & -2000 \\
B1 & 150 & 50 & 7500 \\
B2 & 100 & 50 & 5000 \\
\hline Total & & & $\mathbf{1 0 0 0 0}$ \\
\hline
\end{tabular}

The cost of congestion management through re-dispatch is now $10000 £$.

This example illustrates material impacts of competitive bidding induced by predictable congestion on market outcome. When market operators submit balancing offers and bids according to the expected marginal cost in their location the following market outcomes are impacted in this example :

- The nation-wide forward market price increases from 30 to $50 \mathrm{E} / \mathrm{MWh}$; 
- The amount of congestion to relieve via re-dispatch increases from $100 \mathrm{MWh}$ to 250 MWh;

- The cost of re-dispatch increases from $3000 £$ to $10000 £$.

\section{Conclusion}

These examples show that even though market incentives created by the redispatch approach when congestion is persistent could be perfectly competitive, they eventually create adverse impacts on the market. Even when followed by competitive generators, these incentives may increase nation-wide price, increase the need for congestion relief actions and increase the cost of congestion eventually passed through to customers.

In the long run these bidding incentives create adverse investment incentives. For example, generators located in export-constrained areas that follow the incentives induced by re-dispatch derive profits from selling power at system-wide price and buying power from the TSO at a lower price of the marginal re-dispatch bid. Such profits have no relationship to the generating costs. As a result, export constrained areas may invite investments that are inexpensive to build but highly inefficient to operate. Such investments will be largely funded by the re-dispatch costs socialized among customers.

\section{B. Competitive bidding and market power}

Examples above show that the anticipated congestion managed by the redispatch congestion approach fundamentally modifies bidding behaviour of competitive generators.

Generators' bidding behaviour observed in the GB market and described in section II can be perfectly explained by the incentives induced by the re-dispatch congestion management when constraint situation is anticipated.

In particular, the two types of behaviour identified by Ofgem as evidence of market power exploitation: output manipulation and exploitative bidding, appear to be well in line with the competitive behaviour induced by the anticipation of 
constraint situations. In fact, both these criteria could be difficult to apply in practice for the purposes of Market Power License Condition since none of them by itself or in combination can be considered as a strong evidence of market power exploitation.

As was demonstrated above, the "output manipulation”, that is, seemingly uneconomic scheduling in the nation-wide forward market (scheduling in the forward market of uneconomic plants or not scheduling plants that are in the money) is a natural and competitive behaviour of generators expecting that because of congestion re-dispatch bids and offers will be accepted to resolve congestion in the balancing mechanism, creating an arbitrage opportunity between the unconstrained markets and the market that takes the actual transmission capacity into account. Following the competitive benchmark modified by the re-dispatch congestion management, generators will offer plants located on the import side of the constraint in the forward market above the nation-wide price and may not be able to sell them. Conversely, plants on the export side of the constraint would be selling in the forward markets even if their cost is above the nation-wide price. Thus, “output manipulation” is not directly related to the exploitation of market power, that is, to the use of a dominating market position to impact prices.

Exploitative bidding could also be difficult to establish. In Ofgem’s papers offer and bid prices in Scotland in the constraint situations are often compared with offers and bids of similar plants in England and Wales, the latter being used as competitive benchmarks. However, such comparison disregards the fact that redispatch congestion managed induces different competitive benchmarks on the opposite sides of the constraint when congestion is anticipated, and offer and bid prices on one side of the constraint are not a relevant competitive benchmark for offers and bids on the other side of the constraint.

In presence of congestion, the correct bidding competitive benchmark is the expected cost of delivering a marginal MWh in a given area. It can be determined by the cost of the most expensive unit constrained on or constrained off. Further, in there is a shortage of locational resources available to resolve the constraint the 
locational cost of energy may become determined by scarcity rents based on the value of lost load. Assessing the exploitative bidding relative to this benchmark is not straightforward. Estimation of the locational competitive benchmark requires modeling the entire system. Further, the benchmark is based on each generator's individual expectations of the marginal cost in its area. Such expectations could be very subjective and depend on the information available to generators. In each individual case it could be hard to prove that observed bidding level was excessive relative to the generator's expectation of the local marginal cost.

This does not mean that the Ofgem's concern about market power has no ground. Indeed, high concentration of generators behind an import or an export constraint, as it is the case for example in Scotland, may create serious concerns about potential exploitation of market power beyond the competitive incentives described above. However, the re-dispatch congestion management currently employed in the GB electricity market makes detection of such exploitation extremely difficult. Detection approaches envisaged by Ofgem are likely to regard competitive behaviour as evidence of market power exploitation.

The approach to congestion management needs to be fundamentally reconsidered to resolve the incentive problems described in this section.

\section{IV.EFFICIENT CONGESTION MANAGEMENT MECHANISM}

\section{A. Locational pricing}

Types of market organization that allow managing congestion without creating adverse bidding incentives are the markets with locational clearing prices. In such markets the clearing of market offers and bids is integrated with congestion management at any time horizon, in the day-ahead as well as in the market run close to the real time. Such integrated market clearing compares the power flows resulting from market transactions with the transmission capacity model and ensures that the cleared market solution is feasible with respect to available transmission capacity. 
In case of transmission congestion, the resulting energy prices differ across locations. In such markets, an import constrained area or location is generally cleared at a higher price than the export constrained area or location. These prices reflect the cost of meeting the incremental energy demand at that location or node.

Offers and bids submitted in each location are cleared against the clearing price in the corresponding location. Each accepted offer is paid and each accepted bid pays its corresponding locational clearing price.

This market organization does not have the two main features that create adverse bidding inventives in the re-dispatch approach: a) the existence of two markets accounting differently for available transmission capacity and b) pay-as-bid clearing, that is, paying each accepted balancing offer the price corresponding to this offer.

Indeed, at each stage of the market, a realistic transmission model is taken into account creating no artificial arbitrage between different market stages and creating no consistent incentives for generators to choose between markets when congestion is anticipated.

Regardless of presence of congestion or the side of the constraint, such market organization allows competitive generators to maximize their profits by offering their plants into the market at variable cost of power generation. Once the offer is accepted, each generator's profit is determined by the cleared price and is not directly related to this generator's offer price. Therefore, in markets with locational clearing price there is no incentive to align offers and bids with the expected cost of the last unit running in the area.

There exist numerous examples of electricity markets using this principle. Markets in which for clearing purposes detailed transmission models are used and prices are determined in each transmission node can be found mostly in the US. These include such markets as PJM (Pennsilvania-New Jersey-Maryland Interconnection), New York, New England and the Midwest. Markets of California and Texas have recently adopted a similar design. The electricity pool of New 
Zealand also uses the nodal pricing method. Markets of PJM, California and Texas are particularly interesting as they provide examples of markets originally using redispatch congestion management methods but that have realized that problems caused by such organization warrant a transition towards locational pricing system $[6][7][8]$.

In Europe, the electricity markets in Italy and in the Nordic countries employ simplified zonal transmission capacity models for the locational market clearing. The ongoing market coupling projects in different parts of Europe will also have features of the zonal markets. Such markets share features of both nodal and re-dispatch markets: congestion between large aggregated transmission zones is addressed via locational pricing, while congestion within the transmission zones is dealt with using re-dispatch approach.

\section{B. Financial transmission rights}

Markets with locational clearing prices are often accompanied with the system of financial transmission rights. Financial transmission rights (FTR) ${ }^{3}$ are specified for each couple of injection and withdrawal locations and they pay their holder the difference between the locational clearing prices in these locations. This payment is based on the amount of FTRs and is unrelated to the actual amount of energy production or consumption by the FTR holder. A holder of FTR is therefore hedged against the congestion cost between these two locations for the energy volume equal to the amount of FTRs it holds. For example, in a locational market a generator located in the export-constrained location generally receives a lower price for its energy than generators on the other side of the constraint. When striking bilateral deals with counterparties on the other side of the constraint this generator effectively pays the congestion cost equivalent to the price difference between his and counterparty’s locational prices. An FTR specified between these two locations would allow hedging against this congestion cost.

\footnotetext{
${ }^{3}$ Financial transmission rights have different names in different jurisdictions. For example, in the New York market they are called Transmission Congestion Credits (TCC) and in California market they are called Congestion Revenue Rights (CRR).
} 
In case of a hypothetical locational clearing market in GB, a generator in Scotland holding FTRs between Scotland and England/Wales would effectively secure the amount of energy sales equivalent to its FTR holding at the price of England and Wales regardless of the clearing price in Scotland. It will be exposed to the Scottish prices only for the amount of sales unhedged by FTRs.

The quantity of FTRs allocated to market participants is determined by the available transmission capacity. In markets using complex transmission models for market clearing a procedure called Simultaneous Feasibility Test (SFT) is used to determine transmission capacity simultaneously available for FTR allocation between different locations. Payments associated with FTRs are funded by the congestion revenues collected while clearing the locational markets. As long as the same transmission capacity is used for FTR allocation and for market clearing, congestion revenues should be sufficient to honor all available FTRs ${ }^{4}$.

Mechanisms of allocation of FTRs to market participants vary across markets. Mechanisms can be developed flexible enough to allow seasonal right holding, frequent reconfiguration of rights. Importantly, allocation of financial transmission right can honor transmission rights held by market participants prior to transition to the locational pricing system. In the UK context, FTR allocation can be also used to promote development of renewable in the export-constrained areas.

\section{Ongoing modifications of GB market design}

The GB electricity market design is currently undergoing important modifications. Some of them have elements of the locational pricing mechanism described above and thus may reduce the adverse incentives created by the current congestion management system. These modifications include the Transmission Access Review (TAR) and the introduction of Locational BSUoS. We discuss below how these modifications may improve the situation with congestion incentives and

\footnotetext{
${ }^{4}$ This fundamental result regarding the equivalence between the congestion revenue and the total FTR payments is called revenue adequacy theorem. For more details, see or example [9]
} 
how they compare to the efficient congestion management mechanism based on locational clearing prices.

\section{Transmission Access Review (TAR)}

Ofgem and the Department of Energy and Climate Change are currently working jointly on the project of the Transmission Access Review (TAR). Although the primary objective of TAR is promoting the development of renewable power in Scotland (mostly wind), it tackles some of the related congestion issues as well. In particular, the TAR considers a series of amendments to the current Connection and Use of System Code (CUSC) some of which are intended to allocate the available transmission capacity from the export-constrained areas to the generators on market base [10][11].

In particular, some of the proposed design modifications suggest limiting the amount of transmission rights given to generators in export-constrained areas to sell power nation-wide (entry capacity rights) allowing them to trade the available rights among each other in special auctions at long-term and short-term time scales. It is expected that this will allow using the available export transmission capacity in the most efficient way and will reduce the amount of re-dispatch needed to resolve the export constraints ${ }^{5}$.

Indeed this proposal may help resolving certain re-dispatch incentive problems currently faced in the GB market. In particular, it would allow rationing the available transmission capacity among market participants ahead of time, thus reducing the arbitrage incentives between the forward market and the Balancing Mechanism as a result of constraints.

However, this approach has significant drawbacks. Perhaps the main one is that the auctions for the available export transmission capacity are proposed to be run separately from the energy markets. Experience of similar auctions for transmission capacity in other markets has proven their high inefficiency. The outcomes of the

\footnotetext{
${ }^{5}$ Here we refer to the "Entry Capacity Auction” model which was not eventually retained as a preferred solution.
} 
transmission capacity auctions often turn out to be inefficient the results of the subsequent energy markets. An analogy can be drawn with the explicit auctions for the cross-border capacity in the Continental Europe. These auctions have been proven less efficient than implicit auctions, that is, allocation of transmission integrated with energy market essentially using a locational pricing mechanism[12].

Also, the entry capacity right auction mainly addresses export constraints and may not be helpful in dealing with import constraints. This approach could be difficult to generalize in case if other constraints become important in particular when congestion occurs in a meshed network.

\section{Locational BSUoS}

A tariff component called Balancing Service and Use of System (BSUoS) represents the costs of balancing the system by the TSO. In particular, it includes the costs of offer and bid acceptance in the Balancing Mechanism for the purposes of congestion management.

Currently the BSUoS is socialized across the entire GB market. A recent modification proposal developed by the National Grid suggests allocating the BSUoS component related to the management of transmission constraints to generators behind the constrained boundary, that is, to charge BSUoS on a location basis. According to this proposal, in each hour NGET would compute the cost to relieve the constraint and would assess that cost on a $£$ /MWh basis to generators that were injecting power "behind the constraint" [13].

Although the mechanism of charging locational BSUoS may seem somewhat similar to the locational clearing pricing mechanism, there are many important differences, making the locational BSUoS less efficient in solving the congestion bidding incentive issues than locational clearing prices.

Most importantly, even though the locational BSUoS may reduce profits made by generators in the Balancing Mechanism, it does not eliminate the arbitrage between the unconstrained forward market and the Balancing Mechanism in which 
constraints are addressed. Market participants will still face incentives to shift sales between these two markets when they anticipate congestion, even through these incentives may be muted by the BSUoS.

The locational BSUoS assumes charging generators based on the average congestion cost as opposed to marginal cost of congestion. Thus, the market outcome in the Balancing Mechanism will not be the same as in the locational clearing pricing systems. Elements of pay-as-bid remuneration will still remain and will still provide incentives to bid up to the marginal cost of power in a given location.

The locational BSUoS proposal may be easy to implement for the case of Scotland, but it could be difficult to generalize in case if other constraints become important in particular when congestion occurs in a meshed network. In this situation differentiating the BSUoS charges based on the location of generators "behind" a constraint becomes difficult.

Finally, unlike the locational pricing system that assumes the possibility of hedging against the congestion cost using FTRs, no such hedging possibility will be available to market participants against the locational BSUoS component.

\section{CONCLUSION}

This paper addresses the transmission congestion issues currently becoming acute in the electricity market of the Great Britain. Although it is often assumed that congestion is the GB market is caused or exacerbated by behavior of generators exercising market power, this is not necessarily so. This paper demonstrates that the observed behavior of generators can be employed by generators having no market power when congestion patterns become persistent. Incentives for such behavior are created by the re-dispatch type of congestion management approach used in the GB electricity market. Even though bidding incentives created by this approach in presence of persistent congestion are competitive, they still have adverse impact on 
market outcomes, such as inflated cost of congestion relief, increase of electricity price and inefficient investment in generating capacity.

Curbing these incentives with a new Market Power License Condition does not seem to be an adequate response to the situation. Given the existing re-dispatch congestion management approach, the type of behavior addressed by the MPLC is not specific to market power exercise. Competitive benchmarks suggested for detection of exploitative bidding are irrelevant in case of persistent congestion patterns. MPLC in its current version is likely to be interpreting competitive behavior as exploitation of market power.

Removing the adverse bidding incentives in presence of constraints requires modification of the market organization. In particular, market designs integrating energy market with congestion management using locational clearing prices do not create such incentives. Several electricity markets have historically faced congestion issues similar to those currently experienced in the GB. Comprehensive market redesign was performed in these markets establishing the systems based on locational clearing prices. Examples of such markets are PJM, California and New England. It appears that the congestion issues experienced now in the GB electricity market have reached the point at which a similar fundamental revision of the market design may be warranted.

Some modifications in the market organization are indeed envisaged to address the constraints incentive issues. These modifications include the locational BSUoS and some elements of the Transmission Access Review. Both these modifications could only be a partial solution to the problem and not an integrated and comprehensive approach that is needed to deal with the current constraint situation. Also, they mainly focus on Scottish constraints, in particular the export constraint, and are not flexible enough to accommodate any transmission congestion pattern that may develop in future. These modifications may serve as a quick and partial fix, still requiring a transition to the locational market organization in future. 


\section{REFERENCES}

[1] Ofgem, 2009, “Addressing Market Power Concerns in the Electricity Wholesale Sector - Initial Policy Proposals”

[2] Ofgem, 2009 “Managing Constraints”, Open letter to NG

[3] Ofgem, 2009, “Competition Act Investigation into Scottish Power and Scottish \& Southern Energy”

[4] Ofgem 2009, "Minutes of the Meeting of the Gas and Electricity Markets Authority”

[5] Energy Bill, 19 November 2009

[6] Isemonger, A.G., 2009, "Market Redesign and Technology Upgrade: A Nodal Implementation”, The Electricity Journal, 22:8

[7] Hogan, W., 1998. "Getting the Prices Right in PJM: What the Data Teaches Us,” The Electricity Journal 11:7, pp. 61-67

[8] Perekhodtsev D. and Blumsack S., 2009, "Wholesale electricity markets and generators’ incentives: an international review”, International Handbook on the Economics of Energy, Edward Edgar

[9] Hogan, W., 1992. “Contract Networks for Electric Power Transmission,” Journal of Regulatory Economics 4:3, pp. 211-242

[10] Ofgem and BERR, 2008, “Transmission Access Review - Final Report

[11] Ofgem, 2009, "Enduring Transmission Access Reform - Report”

[12] APX Group, 2006, “APX Group Presents First Results of Trilateral Market Coupling”

[13] Ofgem, 2009, “Locational BSUoS Charging Methodology - GB ECM-18 Impact assessment and consultation” 